\title{
ORIGINAL ARTICLE \\ Cardiovascular response during urodynamics in individuals with spinal cord injury
}

\author{
$\mathrm{N} \mathrm{Liu}^{1,2}, \mathrm{M}-\mathrm{W}$ Zhou $^{1}$, F Biering-Sørensen ${ }^{3}$ and AV Krassioukov ${ }^{2,4,5}$
}

Study design: Retrospective chart review.

Objectives: To establish the frequency and severity of autonomic dysreflexia (AD) during urodynamics among individuals with chronic spinal cord injury (SCI) and to investigate the possible effect of the number of years since SCl on the severity of AD.

Setting: $\mathrm{SCl}$ outpatient clinic.

Methods: A retrospective chart review was undertaken of individuals with $\mathrm{SCl}$ who were seen at an outpatient clinic and could potentially develop an episode of AD (T6 and above). Data regarding age, gender, urodynamic examination, lower urinary tract function, cardiovascular parameters and $\mathrm{SCl}$ were collected. In addition, information on signs and symptoms of AD were retrieved.

Results: A total of 76 individuals with $\mathrm{SCl}$ were examined with blood pressure (BP) monitoring. The majority had cervical SCI (79\%). The mean age was $47.8 \pm 13.9$ years. The median duration after $\mathrm{SCl}$ was 51.5 months. During urodynamics, a total of 48 (63.2\%) individuals showed an increase in systolic $B P>20 \mathrm{~mm} \mathrm{Hg}$, meeting the criteria for AD. Indicators for higher incidences of AD were cervical $\mathrm{SCl}$, being $>2$ years after $\mathrm{SCl}$, the presence of detrusor sphincter dyssynergia (DSD) and low bladder compliance. AD was more severe in individuals with complete (American Spinal Cord Association (ASIA) impairment scale (AIS) A) injuries, worse with greater time after $\mathrm{SCl}$.

Conclusion: Individuals with cervical SCI, DSD, poor bladder compliance or $>2$ years after SCI were associated with a higher possibility of developing $A D$ during urodynamics. Furthermore, $A D$ was more severe in complete (AIS A) individuals and was exacerbated with time after injury.

Spinal Cord (2017) 55, 279-284; doi:10.1038/sc.2016.110; published online 2 August 2016

\section{INTRODUCTION}

Bladder dysfunctions, bowel dysfunctions and abnormal cardiovascular $(\mathrm{CV})$ control contribute significantly to the poor quality of life of individuals after spinal cord injury (SCI), requiring both daily management and continuous medical care. Many individuals with SCI considered the improvement of bladder control, bowel control and the elimination of unpleasant episodes of autonomic dysreflexia (AD) among their priorities for improvement of quality of life. ${ }^{1}$

It is well known that bladder control following SCI is frequently abnormal and requires many individuals to use catheterization for management. ${ }^{2}$ Furthermore, it is recommended that all individuals with SCI undergo urodynamic evaluations in order to determine urinary bladder functionality and make decisions for future management. ${ }^{3}$ Urodynamic evaluation is critical for these individuals' bladder management and upper urinary tract damage prevention, but the procedure may elicit episodes of $\mathrm{AD}$ that could potentially be life threatening. ${ }^{4}$ In fact, stimulation of the urethra/prostate/internal sphincter region is likely to be a more potent stimulus of $\mathrm{AD}$ than just the filling of the bladder involved in urodynamics. ${ }^{5} \mathrm{AD}$ is characterized by episodic hypertension and occurs in up to $90 \%$ of individuals with cervical and high thoracic SCI. ${ }^{6}$ If this condition is misdiagnosed or poorly managed, the consequences can be devastating. Evidence from the literature suggests that episodes of $\mathrm{AD}$ may result in myocardial infarction, ${ }^{7}$ stroke ${ }^{8}$ or even death. ${ }^{8,9}$ The signs and symptoms experienced during $\mathrm{AD}$ can vary and include increased systolic and diastolic blood pressure (SBP and DBP, respectively), bradycardia or tachycardia, pounding headache, cutis anserina, anxiety, flushing and sweating above the neurological level of SCI, malaise and nausea. ${ }^{10}$

According to Curt et al., ${ }^{11}$ urodynamic examination can be regarded as an effective and a standardized diagnostic procedure for provoking an $\mathrm{AD}$ response. Linsenmeyer et al. ${ }^{12}$ found urodynamic examination to be an excellent way to detect whether individuals with SCI are prone to asymptomatic AD. Previous studies revealed incidences of AD during urodynamics, ${ }^{11-16}$ but the diagnostic criteria varied among these studies. Some studies ${ }^{12,13}$ used maximal SBP and DBP as criteria, whereas others ${ }^{11,14-16}$ just used SBP change. The International Standards to document remaining Autonomic Function after Spinal Cord Injury (ISAFSCI) ${ }^{17}$ recommends the diagnostic criteria for $\mathrm{AD}$ as a SBP increase of $>20 \mathrm{~mm} \mathrm{Hg}$ from baseline. Only two previous studies ${ }^{14,15}$ used the same criteria; however, the study by Huang et al. ${ }^{14}$ did not clarify SBP, DBP and heart rate (HR) changes in the $\mathrm{AD}$

\footnotetext{
${ }^{1}$ Department of Rehabilitation Medicine, Peking University Third Hospital, Beijing, China; ${ }^{2}$ International Collaboration on Repair Discoveries (ICORD), Department of Medicine, University of British Columbia, Vancouver, Vancouver, British Columbia, Canada; ${ }^{3}$ Clinic for Spinal Cord Injuries, Rigshospitalet, University of Copenhagen, Copenhagen, Denmark; ${ }^{4}$ Division of Physical Medicine and Rehabilitation, University of British Columbia, Vancouver, British Columbia, Canada and ${ }^{5}$ GF Strong Rehabilitation Centre, Vancouver Coastal Health, Vancouver, British Columbia, Canada

Correspondence: Professor AV Krassioukov, ICORD-BSCC, Department of Medicine, University of British Columbia, 818 West $10 t h$ Avenue, Vancouver, British Columbia V5Z $1 \mathrm{M9}$, Canada.

E-mail: krassioukov@icord.org

Received 1 December 2015; revised 27 May 2016; accepted 7 June 2016; published online 2 August 2016
} 
subgroup but only demonstrated a change in a combination of these $\mathrm{CV}$ parameters in all individuals with and without $\mathrm{AD}$. Therefore, it is difficult to obtain data for evaluation of the severity of $\mathrm{AD}$ in this study.

Giannantoni et al. ${ }^{13}$ compared the mean duration after SCI between individuals with and without $\mathrm{AD}$ and reported no relationship between the occurrence of $\mathrm{AD}$ and the time after SCI. However, this comparison did not provide direct CV parameter changes for different lengths of time after SCI.

The aim of the present study was to establish the frequency and severity of $\mathrm{AD}$ during urodynamics among individuals with chronic SCI at T6 and above (individuals susceptible to $\mathrm{AD}$ ). We also examined the possible effect of time following SCI on the $\mathrm{CV}$ responses elicited by urodynamics. In addition, we analyzed the $\mathrm{CV}$ responses in relation to lower urinary tract (LUT) parameters included in ISAFSCI, ${ }^{17}$ as well as the urodynamics parameters according to the International Spinal Cord Injury Urodynamic Data Set. ${ }^{18}$

\section{MATERIALS AND METHODS}

Following study protocol approval by the Clinical Research Ethics Board, a retrospective chart review was undertaken of all SCI individuals above T6 who underwent urodynamic examination in conjunction with $\mathrm{BP}$ monitoring. The review lasted from January 2011 to December 2012.

\section{Data collection}

Data collected about each individual included age, gender, date of urodynamic examination, duration of SCI, neurological level of lesion and the American Spinal Cord Association (ASIA) Impairment Scale (AIS). These variables align with the International Spinal Cord Injury Core Data Set. ${ }^{19} \mathrm{CV}$ parameters for $\mathrm{BP}$ and $\mathrm{HR}$ at baseline and during urodynamics were collected, as well as noted symptoms or signs of AD. In addition, all charts were specifically reviewed for antihypertensive medications.

During urodynamic procedures, individuals underwent continuous BP and HR monitoring (Dinamap 100, GE, Fairfield, CT, USA) recorded at intervals of $1 \mathrm{~min}$ starting from the position of individuals on the urodynamic table (baseline), during catheter insertion and during all stages of the urodynamic examination. The full printout of the $\mathrm{CV}$ parameters during the procedure was

Table 1 Study population characteristics

\begin{tabular}{lcc}
\hline Characteristics & & \\
\hline Age at examination (years) & $47.8 \pm 13.9$ & $(19-80)$ \\
Duration since spinal cord lesion (months) & 51.5 & $(2-532)$ \\
& & \\
Gender & & \\
Male & 66 & $86.8 \%$ \\
Female & 10 & $13.2 \%$ \\
& & \\
Etiology & & \\
Sports & 11 & $14.5 \%$ \\
Assault & 4 & $5.2 \%$ \\
Transport & 37 & $48.7 \%$ \\
Fall & 11 & $14.5 \%$ \\
Other traumatic cause & 2 & $2.6 \%$ \\
Non-traumatic cause & 11 & $14.5 \%$ \\
& & \\
Neurological category & & \\
C1-C8 AIS A & 30 & $39.5 \%$ \\
C1-C8 AIS B-D & 30 & $39.5 \%$ \\
T1-T6 AIS A & 12 & $15.8 \%$ \\
T1-T6 AIS B-D & 4 & $5.2 \%$ \\
\hline Abbreviation: AIS, American Spina &
\end{tabular}

Abbreviation: AIS, American Spinal Injury Association Impairment Scale. stored in the patient's chart in addition to the following CV parameters documented on the urodynamic log: BP and HR at baseline, first sensation, leakage point, and for BP the overall maximum BP reached. Any symptoms or signs of $\mathrm{AD}$ were documented to distinguish silent and symptomatic $\mathrm{AD}$.

According to the diagnostic criteria for $\mathrm{AD}$ in the ISAFSCI, ${ }^{17}$ individuals were divided into two subgroups: an $\mathrm{AD}$ subgroup (increase in $\mathrm{SBP}$ of $>20 \mathrm{~mm} \mathrm{Hg}$ ) and a Non-AD subgroup (increase in SBP $\leqslant 20 \mathrm{~mm} \mathrm{Hg}$ or a decrease in SBP). The CV parameters in the whole group, the $\mathrm{AD}$ subgroup and the Non- $\mathrm{AD}$ subgroup were analyzed, and comparisons were made between the $\mathrm{AD}$ and Non-AD subgroups.

Collection of LUT function data was collected in the Lower Urinary Tract, Bowel and Sexual Function Table, in accordance with the ISAFSCI. ${ }^{17}$ The variables for the bladder-emptying method originated from the definition in the International Spinal Cord Injury Lower Urinary Tract Function Basic Data Set. ${ }^{20}$ Only the main emptying method was collected for the SCI individuals in our study. The urodynamic parameters aligned with the International Spinal Cord Injury Urodynamic Basic Data Set. ${ }^{18}$ To facilitate our reporting, we collapsed some items in these variables, that is, bladder sensation was recorded as present or absent, detrusor function as neurogenic detrusor overactivity (NDO) or non-NDO and urethral function as detrusor sphincter dyssynergia (DSD) or non-DSD. Bladder compliance described the relationship between the change in bladder volume and the change in detrusor pressure, with low bladder compliance defined as $<10 \mathrm{ml}$ per $\mathrm{cm}$ of water.

Urodynamic parameters were also collected during urodynamic evaluations (Aquarius TT, Laborie, Montreal, QC, Canada). Evaluations were carried out by the same group of registered nurses and urologist according to the principles set forth by the International Continence Society. ${ }^{21}$ The examination consisted of cystometry with warm water $\left(37^{\circ} \mathrm{C}\right)$ at a filling rate of $30 \mathrm{ml} \mathrm{min}^{-1}$ through a 6-F double lumen catheter while the patients were supine. Abdominal pressure was measured with a $10-\mathrm{F}$ intrarectal balloon catheter. Pelvic floor electromyography was recorded during cystometry with a bipolar wire electrode in the urethral sphincter. Filling was stopped when the patients reported sensation of fullness, at the moment of urine leakage or when bladder filling reached $500 \mathrm{ml}$.

\section{Statistical analyses}

Statistical analysis was conducted using SPSS 19.0 (IBM-SPSS, Chicago, IL, USA) as follows: the data of continuous variables are expressed as mean \pm s.d. or median. Categorical variables are expressed as percentages and absolute frequencies. For continuous variables, statistical analyses were carried out using Student's $t$-test or analysis of variance if normal distribution was present. Otherwise Mann-Whitney $U$-test or Kruskal-Wallis $H$-test for nonparametric comparisons was used. A chi-square test was performed to compare categorical variables. Correlations of SBP and years after SCI were analyzed with the Spearman method. Significance level was set at $P<0.05$.

\section{RESULTS}

\section{General presentation of $\mathrm{AD}$ during urodynamics}

A total of 76 individuals with SCI above T6 were examined with BP monitoring during urodynamics at a urology outpatient clinic from January 2011 to December 2012. The mean age was $47.8 \pm 13.9$ years. None of the individuals were on any continuous antihypertensive medications. However, all of them had standing order for management of episodes of $\mathrm{AD}$ that included either nifedipine or captopril on as needed basis. None of the SCI individuals took medication prior to the urodynamics. The majority individuals in the present study had cervical SCI (79\%; 60/76), and because of poor hand function most of them used reflex triggering $(40 \% ; 24 / 60)$ or indwelling catheter (37\%; 22/60) for bladder management (see Table 4$)$. The median duration of injury was 51.5 months. The standardized demographic characteristics, neurological level of lesion and AIS of the study population are shown in Table 1. In the AD subgroup, SBP increased from $124.4 \pm 20.4$ to $176.0 \pm 31.8 \mathrm{~mm} \mathrm{Hg}$, whereas in the Non-AD subgroup it increased from $121.0 \pm 16.0$ to $130.0 \pm 17.3 \mathrm{~mm} \mathrm{Hg}$. 
The CV parameters for the whole group, the Non-AD subgroup and the $\mathrm{AD}$ subgroup are shown in Table 2. During urodynamic examination, $48(63.2 \%)$ individuals experienced an SBP elevation $>20 \mathrm{~mm} \mathrm{Hg}$, which met the criteria for AD diagnosis. The highest BP recorded during urodynamics was $242 / 129 \mathrm{~mm} \mathrm{Hg}$. Among the AD subgroup, $28(58.3 \%)$ individuals had symptoms that included headache, sweating and flushing, whereas the remaining $(41.7 \%)$ had asymptomatic $\mathrm{AD}$, also known as silent $\mathrm{AD} .^{22,23}$

\section{Level and severity of SCI and AD}

Table 3 shows the comparison between incidence of $\mathrm{AD}$ and the average changes in SBP, DBP and HR by different injury levels (C1-C8 vs T1-T6), completeness of injury (AIS A vs AIS B-D) and duration after injury ( $<2$ years vs $>2$ years). The incidence of $\mathrm{AD}$ was statistically significantly higher for individuals with cervical SCI and also those with $>2$ years after injury $(P=0.003$ and $P<0.001$, respectively). The SBP change was significantly larger in cervical than in thoracic SCI $(P=0.021)$, whereas DBP and HR changes did not reveal statistically significant differences. If only comparing SBP changes in the $\mathrm{AD}$ subgroup, no significant difference was found between cervical and thoracic SCI. Both SBP and DBP changes

Table 2 Cardiovascular parameters of the study population during urodynamics

\begin{tabular}{lccc}
\hline Items & Whole group & Non-AD subgroup & AD subgroup \\
\hline Number & 76 & 28 & 48 \\
SBP baseline (mm Hg) & $120.7 \pm 18.8$ & $121.0 \pm 16.0$ & $120.4 \pm 20.4$ \\
DBP baseline (mm Hg) & $70.0 \pm 12.8$ & $70.3 \pm 12.9$ & $70.0 \pm 12.9$ \\
HR baseline (b.p.m.) & $69.3 \pm 14.4$ & $76.2 \pm 13.0^{* *}$ & $65.3 \pm 13.7^{* *}$ \\
SBP maximal (mm Hg) & $159.1 \pm 35.3$ & $130.0 \pm 17.3^{* * *}$ & $176.0 \pm 31.8^{* * *}$ \\
DBP at SBP maximal (mm Hg) & $84.4 \pm 18.0$ & $71.9 \pm 13.5^{* * *}$ & $91.7 \pm 16.3^{* * *}$ \\
HR at SBP maximal (b.p.m.) & $61.9 \pm 13.2$ & $69.4 \pm 12.6^{* * *}$ & $57.5 \pm 11.5^{* * *}$ \\
SBP change (mm Hg) & $38.4 \pm 28.3$ & $8.9 \pm 8.5^{* * *}$ & $55.6 \pm 20.5^{* * *}$ \\
DBP change (mm Hg) & $14.3 \pm 15.2$ & $1.5 \pm 9.1^{* * *}$ & $21.8 \pm 12.9^{* * *}$ \\
HR change (b.p.m.) & $-7.5 \pm 10.1$ & $-6.8 \pm 9.4$ & $-7.8 \pm 10.5$
\end{tabular}

Abbreviations: AD, autonomic dysreflexia; b.p.m., beats per minute; DBP, diastolic blood pressure; HR, heart rate; SBP, systolic blood pressure.

$A D$ is defined as SBP increase $>20 \mathrm{~mm} \mathrm{Hg}$.

${ }^{* *} P<0.01$ and ${ }^{* * *} P<0.001$ (comparison between non-AD and AD subgroups). were significantly larger $(P<0.001$ and $P<0.001$, respectively) in individuals $>2$ years after SCI. There were no statistically significant changes, however, in HR. Interestingly, although no difference was found for incidence of $\mathrm{AD}$ in relation to injury completeness according to AIS grades, SBP change was significantly larger $(P=0.020)$ and HR decreased more $(P=0.004)$ in those with complete (AIS A) than in those with incomplete SCI. AIS A individuals with $\mathrm{AD}$ had a significantly larger increase in SBP than AIS B-D individuals with AD $(P=0.024)$. The SBP increase in individuals $>2$ years after injury was significantly higher than in individuals $<2$ years after injury $(P=0.043)$ in the $\mathrm{AD}$ subgroup. In addition, SBP change showed significantly positive correlations with years after injury in the whole group (Figure 1) and the AD subgroup (Figure 2).

\section{LUT functions and $\mathrm{AD}$}

The divisions of the study population into subgroups by LUT function parameters are shown in Table 4. For $\mathrm{AD}$ incidence and changes in $\mathrm{SBP}, \mathrm{DBP}$ and HR in the AD subgroup, no significant differences were found between individuals with or without awareness of the need to empty the bladder, between individuals with or without the ability to prevent leakage and among three different bladder-emptying methods.

The relationship between $\mathrm{AD}$ incidence, $\mathrm{CV}$ parameter changes and urodynamic parameters is shown in Table 5. Incidence of $\mathrm{AD}$ was higher in individuals with low bladder compliance and DSD $(P=0.027$ and $P=0.007$, respectively). SBP changes were likewise significantly larger in individuals with and without $\mathrm{AD}$ when the bladder compliance was low and DSD was present $(P=0.009$ and $P=0.007$, respectively). However, if only analyzing individuals who developed AD, no significant differences were found. Furthermore, there were no statistically significant differences between individuals with and without $\mathrm{AD}$ when comparing detrusor leak point pressure, maximum detrusor pressure, cystometric bladder capacity and postvoid residual volume. In addition, in the whole group and the $\mathrm{AD}$ subgroup, we found no correlation between SBP increase and bladder pressure or capacity.

\section{DISCUSSION}

Previous studies ${ }^{11,12}$ have established the use of urodynamic examination as an appropriate screening tool for AD. Our study further

Table 3 Comparison of autonomic dysreflexia incidence and cardiovascular parameters during urodynamic investigation by injury characteristics

\begin{tabular}{|c|c|c|c|c|c|c|c|c|}
\hline \multirow[t]{2}{*}{ Items } & \multirow[t]{2}{*}{$\mathrm{N}$} & \multirow[t]{2}{*}{ Incidence of $A D, \%$ (n) } & \multicolumn{2}{|c|}{ SBP change $(\mathrm{mm} \mathrm{Hg})$} & \multicolumn{2}{|c|}{$D B P$ change $(\mathrm{mm} \mathrm{Hg})$} & \multicolumn{2}{|c|}{ HR change (b.p.m.) } \\
\hline & & & Whole group & $A D$ subgroup & Whole group & $A D$ subgroup & Whole group & $A D$ subgroup \\
\hline \multicolumn{9}{|l|}{ Injury level } \\
\hline $\mathrm{C} 1-\mathrm{C} 8$ & 60 & $71.7(43)^{* *}$ & $42.6 \pm 29.5^{*}$ & $57.0 \pm 21.0$ & $15.0 \pm 15.8$ & $21.4 \pm 12.9$ & $-6.2 \pm 8.6$ & $-7.3 \pm 9.7$ \\
\hline T1-T6 & 16 & $31.3(5)^{* *}$ & $22.7 \pm 15.7^{*}$ & $43.4 \pm 10.1$ & $11.9 \pm 12.9$ & $25.6 \pm 12.9$ & $-12.0 \pm 13.8$ & $-12.4 \pm 16.7$ \\
\hline \multicolumn{9}{|c|}{ Completeness of injury } \\
\hline AIS A & 42 & $66.7(28)$ & $44.8 \pm 28.5^{*}$ & $60.8 \pm 20.5^{*}$ & $15.6 \pm 16.2$ & $22.9 \pm 13.6$ & $-9.9 \pm 9.7^{* *}$ & $-9.1 \pm 9.0$ \\
\hline AIS B-D & 34 & $58.8(20)$ & $30.5 \pm 26.4^{*}$ & $48.3 \pm 18.4^{*}$ & $12.7 \pm 14.0$ & $20.3 \pm 12.0$ & $-4.4 \pm 9.8^{* *}$ & $-6.0 \pm 12.4$ \\
\hline \multicolumn{9}{|c|}{ Years after injury } \\
\hline$<2$ years & 31 & $38.7(12)^{* * *}$ & $22.5 \pm 23.8^{* * *}$ & $46.8 \pm 18.7^{*}$ & $6.8 \pm 12.5^{* * *}$ & $17.2 \pm 9.9$ & $-7.9 \pm 9.7$ & $-10.3 \pm 12.6$ \\
\hline$>2$ years & 45 & $80.0(36)^{* * *}$ & $49.4 \pm 26.0 * * *$ & $58.6 \pm 20.4^{*}$ & $19.5 \pm 14.8^{* * *}$ & $23.3 \pm 13.5$ & $-7.1 \pm 10.4$ & $-7.0 \pm 9.8$ \\
\hline
\end{tabular}

Abbreviations: AD, autonomic dysreflexia; AIS, American Spinal Injury Association Impairment Scale; b.p.m., beats per minute; DBP, diastolic blood pressure; HR, heart rate; SBP, systolic blood pressure.

${ }^{*} P<0.05,{ }^{* *} P<0.01$ and ${ }^{* * *} P<0.001$. 


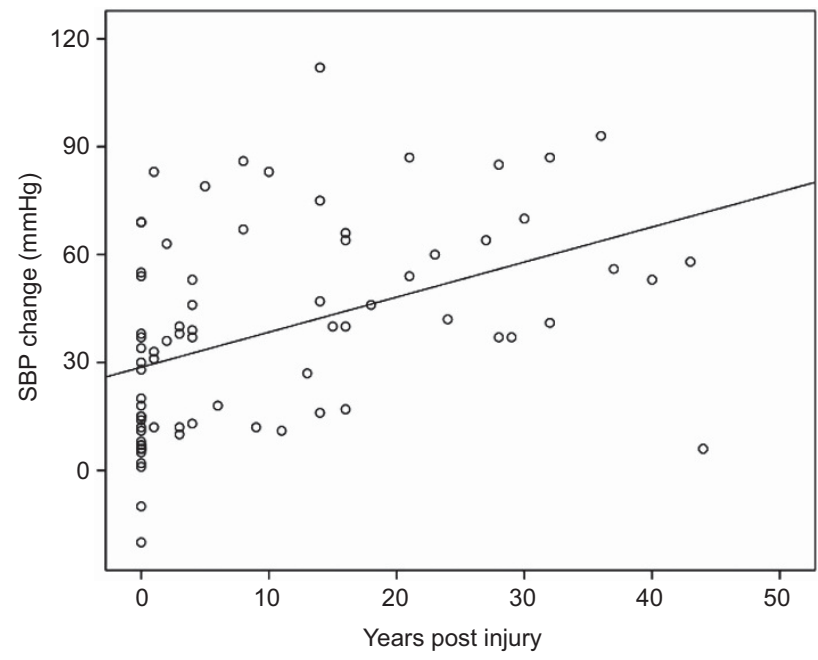

Figure 1 Scatter diagram shows the positive correlation $(r=0.543$, $P<0.001$ ) of SBP change with years following SCl. A duration of $<1$ year after injury was assigned as 0 , between 1 and 2 years was assigned as 1 and so on.

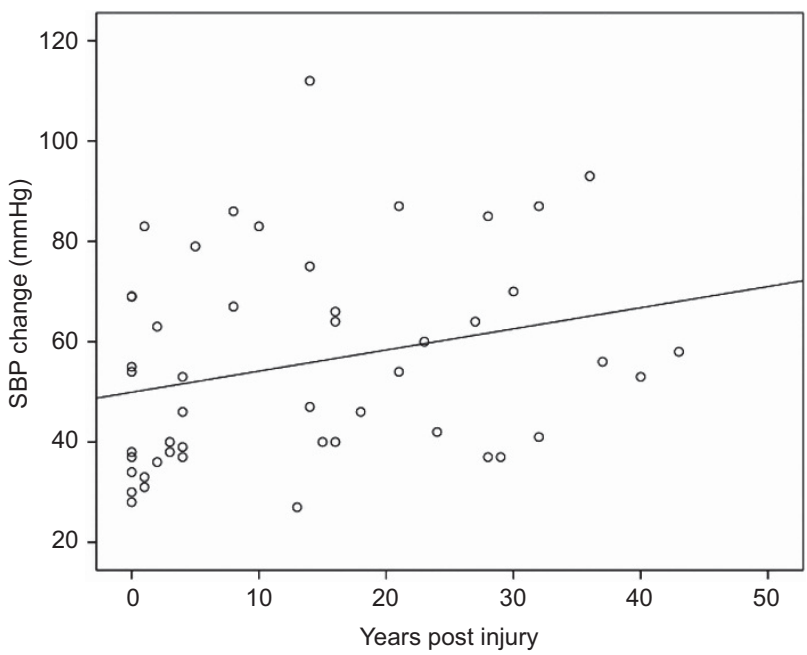

Figure 2 Scatter diagram shows the positive correlation $\quad r=0.350$, $P=0.015)$ of SBP change with years following $\mathrm{SCl}$ in individuals who developed autonomic dysreflexia. A duration of $<1$ year after injury was assigned as 0 , between 1 and 2 years was assigned as 1 and so on.

supports that BP monitoring during urodynamics is highly recommended as an $\mathrm{AD}$ screening tool for individuals with SCI. In our study, $48(63.2 \%)$ individuals showed SBP elevation by $>20 \mathrm{~mm} \mathrm{Hg}$, indicating an onset of AD. Among them, $28(58.3 \%)$ had symptoms, whereas the remaining 20 individuals could be categorized as having silent $\mathrm{AD} .^{22,23}$

Previously, the incidence of silent $\mathrm{AD}$ during urodynamics was reported as $43-50 \%,{ }^{12,24}$ which is similar to our finding. Hence, urodynamics could be considered as a screening tool for individuals with $\mathrm{SCI}$ prone to $\mathrm{AD}$, especially for those whose $\mathrm{AD}$ is asymptomatic. In addition to urodynamics, bowel programs ${ }^{22}$ and sperm retrieval $^{23}$ also could elicit episodes of silent $\mathrm{AD}$. Therefore, routine BP monitoring during these iatrogenic procedures is highly recommended.

When making comparisons between $\mathrm{AD}$ incidence and the neurological level of lesion, $\mathrm{AD}$ was seen more frequently in those with cervical SCI, consistent with observations in previous studies. ${ }^{13,14}$ The SBP increase also revealed a larger increase in cervical SCI, in accordance with Huang et al. ${ }^{14}$; however, the SBP increase in individuals with $\mathrm{AD}$ demonstrated no significant difference between cervical and thoracic SCI, instead reflecting a similar severity of $\mathrm{AD}$ irrespective of the neurological level above T6.

Completeness of injury according to the AIS grade was also regarded as a contributing factor for the development of AD. Typically individuals with AIS A have more frequent and more severe bouts of AD. ${ }^{6,11}$ Previous studies, ${ }^{13,14}$ however, have not verified this hypothesis during urodynamics. In our study, although the incidence of $\mathrm{AD}$ did not show a statistically significant difference between complete (AIS A) and incomplete (AIS B-D) injuries, the SBP increase was larger and the HR decrease more pronounced in those with complete SCI. Although we only found a trend as a result of our study, it may be postulated that $\mathrm{AD}$ is more severe in those with complete SCI.

The correlation of $\mathrm{AD}$ frequency and severity with duration postSCI is not well described. In an animal experiment, it was suggested that $\mathrm{AD}$ severity increased with time after injury. ${ }^{25}$ However, in a study conducted by Giannantoni et al., ${ }^{13}$ no correlation was found between $\mathrm{AD}$ and duration of SCI. In our study, the incidence of $\mathrm{AD}$ and change in SBP were both higher in individuals $>2$ years after SCI. Furthermore, we also found a positive correlation between SBP change and years after injury, further suggesting that $\mathrm{AD}$ worsens with time after SCI. The possible reason for the discrepancy between our and the previous study ${ }^{13}$ may be that the median duration after SCI exceeded 4 years in our study but only 2 years in the previous study. ${ }^{13}$

Three main topics of LUT function include awareness of the need to empty the bladder, ability to prevent leakage and bladder-emptying methods. In our study, no statistically significant differences were found between these LUT function parameters and either incidence of $\mathrm{AD}$ or $\mathrm{CV}$ parameter changes. One previous study ${ }^{13}$ likewise found that $\mathrm{AD}$ presence was unrelated to bladder management. Therefore, we can conclude that $\mathrm{AD}$ occurrence seems not to be influenced by bladder awareness, urinary incontinence and bladder-emptying methods.

In our study, $\mathrm{AD}$ incidence was statistically significantly higher in those individuals with DSD and low bladder compliance. The impact of urethral function and bladder compliance with respect to the development of $\mathrm{AD}$ remains controversial. The study by Giannantoni et al. ${ }^{13}$ showed no correlations between $\mathrm{AD}$ and incidence of DSD or low bladder compliance. However, Huang et al. ${ }^{14}$ revealed that SBP changes were significantly larger in individuals with DSD and severely impaired bladder compliance. Perkash ${ }^{26}$ also found that SBP increase was significantly lower after transurethral modified sphincterotomy than before transurethral modified sphincterotomy, further supporting the relationship between $\mathrm{AD}$ and DSD. When comparing SBP changes in relation to DSD and low bladder compliance in the whole group, SBP changes were larger than those reported in a previous study by Huang et al. ${ }^{14}$ However, the results from the previous study ${ }^{14}$ were based on the combination of results from individuals with and without $\mathrm{AD}$; thus they could not demonstrate a possible relationship to the severity of $\mathrm{AD}$. Considering that $\mathrm{SBP}$ increased in the $\mathrm{AD}$ subgroup only, we found no significant differences regarding severity of the $\mathrm{AD}$ between individuals with and without DSD or between individuals with and without low bladder compliance. In our study, neither AD incidence nor SBP increase in $\mathrm{AD}$ individuals was significantly different between those with or without NDO. Correspondingly, Linsenmeyer et al. ${ }^{12}$ reported that maximum detrusor pressure and bladder capacity were not statistically different between groups with 
Table 4 Comparison of autonomic dysreflexia incidence and cardiovascular parameters during urodynamic investigation by lower urinary tract function from International Standards to document remaining Autonomic Function after Spinal Cord Injury (ISAFSCI)

\begin{tabular}{|c|c|c|c|c|c|c|c|c|}
\hline \multirow[t]{2}{*}{ Items } & \multirow[t]{2}{*}{$\mathrm{N}$} & \multirow[t]{2}{*}{ Incidence of $A D, \%$ (n) } & \multicolumn{2}{|c|}{ SBP change ( $\mathrm{mm} \mathrm{Hg}$ ) } & \multicolumn{2}{|c|}{$D B P$ change $(\mathrm{mm} \mathrm{Hg})$} & \multicolumn{2}{|c|}{ HR change (b.p.m.) } \\
\hline & & & Whole group & $A D$ subgroup & Whole group & $A D$ subgroup & Whole group & $A D$ subgroup \\
\hline \multicolumn{9}{|c|}{ Awareness of the need to empty the bladder } \\
\hline Present & 32 & $59.4(19)$ & $32.2 \pm 25.8$ & $49.8 \pm 17.2$ & $12.6 \pm 13.1$ & $19.4 \pm 11.4$ & $-5.6 \pm 9.0$ & $-7.9 \pm 10.9$ \\
\hline Absent & 44 & $65.9(29)$ & $42.9 \pm 29.5$ & $59.4 \pm 21.8$ & $15.6 \pm 16.6$ & $23.3 \pm 13.7$ & $-8.8 \pm 10.7$ & $-7.8 \pm 10.4$ \\
\hline \multicolumn{9}{|l|}{ Ability to prevent leakage } \\
\hline No & 43 & $69.8(30)$ & $43.7 \pm 27.1$ & $57.3 \pm 20.7$ & $14.8 \pm 15.4$ & $20.6 \pm 13.4$ & $-9.5 \pm 11.3$ & $-9.9 \pm 10.7$ \\
\hline Yes & 33 & $54.5(18)$ & $31.5 \pm 28.7$ & $52.8 \pm 20.3$ & $13.7 \pm 15.1$ & $23.8 \pm 12.0$ & $-4.8 \pm 7.6$ & $-4.4 \pm 9.5$ \\
\hline \multicolumn{9}{|l|}{ Bladder-emptying method } \\
\hline Bladder reflex triggering & 26 & $69.2(18)$ & $44.8 \pm 29.1$ & $59.6 \pm 22.1$ & $15.8 \pm 16.2$ & $22.1 \pm 14.4$ & $-6.7 \pm 7.4$ & $-8.6 \pm 8.1$ \\
\hline Intermittent catheterization & 23 & $65.2(15)$ & $37.4 \pm 26.4$ & $52.5 \pm 19.4$ & $14.2 \pm 13.5$ & $20.0 \pm 10.4$ & $-9.7 \pm 13.7$ & $-8.8 \pm 12.9$ \\
\hline Indwelling catheter & 27 & $55.6(15)$ & $33.2 \pm 28.9$ & $53.9 \pm 20.1$ & $13.0 \pm 16.0$ & $23.2 \pm 13.9$ & $-6.3 \pm 8.6$ & $-5.9 \pm 10.9$ \\
\hline
\end{tabular}

Abbreviations: AD, autonomic dysreflexia; b.p.m., beats per minute; DBP, diastolic blood pressure; HR, heart rate; SBP, systolic blood pressure.

Table 5 Comparison of autonomic dysreflexia incidence and cardiovascular parameters during urodynamic investigation by urodynamic parameters from the International Spinal Cord Injury Urodynamic Basic Data Set

\begin{tabular}{|c|c|c|c|c|c|c|c|c|}
\hline \multirow[t]{2}{*}{ Items } & \multirow[t]{2}{*}{$\mathrm{N}$} & \multirow[t]{2}{*}{ Incidence of $A D, \%$ (n) } & \multicolumn{2}{|c|}{ SBP change $(\mathrm{mm} \mathrm{Hg})$} & \multicolumn{2}{|c|}{ DBP change $(\mathrm{mm} \mathrm{Hg})$} & \multicolumn{2}{|c|}{ HR change (b.p.m.) } \\
\hline & & & Whole group & $A D$ subgroup & Whole group & $A D$ subgroup & Whole group & $A D$ subgroup \\
\hline \multicolumn{9}{|c|}{ Bladder sensation } \\
\hline Present & 30 & $56.7(17)$ & $33.1 \pm 24.9$ & $51.1 \pm 17.8$ & $12.0 \pm 13.0$ & $19.1 \pm 11.5$ & $-6.2 \pm 9.1$ & $-8.5 \pm 11.3$ \\
\hline Absent & 46 & $67.4(31)$ & $41.9 \pm 30.1$ & $58.1 \pm 21.6$ & $15.9 \pm 16.4$ & $23.3 \pm 13.5$ & $-8.2 \pm 10.7$ & $-7.4 \pm 10.2$ \\
\hline \multicolumn{9}{|c|}{ Detrusor function } \\
\hline NDO & 54 & $68.5(37)$ & $42.4 \pm 27.0$ & $56.6 \pm 20.2$ & $16.6 \pm 16.4^{*}$ & $23.6 \pm 13.7$ & $-8.2 \pm 11.0$ & $-7.7 \pm 11.0$ \\
\hline Non-NDO & 22 & $50.0(11)$ & $28.5 \pm 29.6$ & $52.2 \pm 21.9$ & $8.7 \pm 10.8^{*}$ & $15.6 \pm 6.7$ & $-5.7 \pm 7.2$ & $-8.3 \pm 9.1$ \\
\hline \multicolumn{9}{|c|}{ Low bladder compliance } \\
\hline Yes & 50 & $72.0(36)^{*}$ & $44.5 \pm 26.8^{* *}$ & $56.9 \pm 20.8$ & $17.9 \pm 14.7^{* *}$ & $23.0 \pm 13.7$ & $-7.9 \pm 11.1$ & $-7.2 \pm 10.7$ \\
\hline No & 26 & $46.2(12)^{*}$ & $26.7 \pm 27.9^{* *}$ & $51.8 \pm 19.6$ & $7.4 \pm 13.8^{* *}$ & $18.3 \pm 9.6$ & $-6.6 \pm 7.9$ & $-9.8 \pm 10.3$ \\
\hline \multicolumn{9}{|c|}{ Urethral function } \\
\hline DSD & 59 & $71.2(42)^{* *}$ & $42.8 \pm 28.1^{* *}$ & $56.2 \pm 21.0$ & $15.5 \pm 15.6$ & $21.7 \pm 12.9$ & $-7.7 \pm 9.2$ & $-8.4 \pm 10.5$ \\
\hline Non-DSD & 17 & $35.3(6)^{* *}$ & $23.2 \pm 24.2^{* *}$ & $51.2 \pm 17.4$ & $10.4 \pm 13.3$ & $22.5 \pm 13.6$ & $-6.5 \pm 12.9$ & $-3.5 \pm 10.8$ \\
\hline
\end{tabular}

Abbreviations: AD, autonomic dysreflexia; b.p.m., beats per minute; DBP, diastolic blood pressure; DSD, detrusor sphincter dyssynergia; HR, heart rate; NDO, neurogenic detrusor overactivity; $\mathrm{SBP}$, systolic blood pressure.

${ }^{*} P<0.05$ and ${ }^{* *} P<0.01$.

and without AD. However, their study emphasized that the increase in $\mathrm{BP}$ in individuals with uninhibited contractions was not caused by bladder distension itself but rather by bladder distension triggering an uninhibited bladder contraction. The relationship between $\mathrm{AD}$ and NDO needs further investigation.

Although our center has an established urodynamic protocol that includes urological procedure, $\mathrm{CV}$ monitoring and follow-up in case of $\mathrm{AD}$ development, we have to acknowledge a few possible limitations in the present study. We conducted a retrospective data collection, which is obviously a limiting factor of the study with respect to the collection of information on the developed symptoms of AD. Data presented in the study were collected from the records of the urodynamic logs that are typically made by nursing personnel during the procedure. In addition, we used maximal SBP change in individuals who developed $\mathrm{AD}$, which could only reveal the peak response in an episode of $\mathrm{AD}$. We did not examine the time point when individuals exceeded the SBP increase threshold (that is, $20 \mathrm{~mm} \mathrm{Hg}$ ) that would represent the onset of an episode of AD nor did we calculate the duration of the episode of $\mathrm{AD}$. Furthermore, presently there is no technology available at our center to combine and simultaneously illustrate the urodynamic logs and CV data. This point would need to be clarified in a further prospective study that utilizes more precise, continuous $\mathrm{BP}$ monitoring.

\section{CONCLUSION}

$\mathrm{BP}$ monitoring at 1-min intervals during urodynamic investigations is highly recommended to aid in the screening of $\mathrm{AD}$, especially in cases of asymptomatic, silent $\mathrm{AD}$. The results of the present study suggest 
that individuals with cervical SCI, DSD, poor bladder compliance and $>2$ years after SCI are associated with a higher possibility of developing $\mathrm{AD}$ during urodynamic examinations. The episode of $\mathrm{AD}$ is more severe in individuals with complete (AIS A) SCI and is exacerbated with time after injury. Therefore, close monitoring and caution should be taken in individuals who present with these features.

\section{DATA ARCHIVING}

There were no data to deposit.

\section{CONFLICT OF INTEREST}

The authors declare no conflict of interest.

\section{ACKNOWLEDGEMENTS}

Dr Nan Liu was supported by State scholarship from China Scholarship Council to the Laboratory of Dr Krassioukov, International Collaboration on Research Discoveries (ICORD), University of British Columbia, Canada; Dr Andrei Krassioukov is supported as the Endowed Chair of Rehabilitation Medicine University of British Columbia and by grants from the Canadian Heart and Stroke Foundation, Canadian Institute of Health Research, Canadian Foundation for Innovation, Craig Neilsen Foundation and Christopher and Dana Reeve Foundation. We thank support from the staff of the Blusson Spinal Cord Clinic during the preparation of this manuscript-Ms Renee Fougere, Ms Teresa Lim and Ms Colleen McLean.

1 Anderson KD. Targeting recovery: priorities of the spinal cord-injured population. J Neurotrauma 2004; 21: 1371-1383.

2 Consortium for Spinal Cord Medicine. Bladder management for adults with spinal cord injury: a clinical practice guideline for health-care providers. J Spinal Cord Med 2006; 29: 527-573.

3 Watanabe T, Rivas DA, Chancellor MB. Urodynamics of spinal cord injury. Urol Clin North Am 1996; 23: 459-473.

4 Phillips AA, Krassioukov AV. Contemporary cardiovascular concerns after spinal cord injury: mechanisms, maladaptations, and management. J Neurotrauma 2015; 32: 1927-1942.

5 Liu N, Fougere R, Zhou MW, Nigro MK, Krassioukov AV. Autonomic dysreflexia severity during urodynamics and cystoscopy in individuals with spinal cord injury. Spinal Cord 2013; 51: 863-867.

6 Krassioukov A, Warburton DE, Teasell R, Eng JJ. A systematic review of the management of autonomic dysreflexia after spinal cord injury. Arch Phys Med Rehabil 2009; 90: 682-695.
7 Ho CP, Krassioukov AV. Autonomic dysreflexia and myocardial ischemia. Spinal Cord 2010; 48: 714-715.

8 Eltorai I, Kim R, Vulpe M, Kasravi H, Ho W. Fatal cerebral hemorrhage due to autonomic dysreflexia in a tetraplegic patient: case report and review. Paraplegia 1992; 30: 355-360.

9 Wan D, Krassioukov AV. Life-threatening outcomes associated with autonomic dysreflexia: a clinical review. J Spinal Cord Med 2014; 37: 2-10.

10 Calder KB, Estores IM, Krassioukov A. Autonomic dysreflexia and associated acute neurogenic pulmonary edema in a patient with spinal cord injury: a case report and review of the literature. Spinal Cord 2009; 47: 423-425.

11 Curt A, Nitsche B, Rodic B, Schurch B, Dietz V. Assessment of autonomic dysreflexia in patients with spinal cord injury. J Neurol Neurosurg Psychiatry 1997; 62: 473-477.

12 Linsenmeyer TA, Campagnolo DI, Chou IH. Silent autonomic dysreflexia during voiding in men with spinal cord injuries. J Urol 1996; 155: 519-522.

13 Giannantoni A, Di Stasi SM, Scivoletto G, Mollo A, Silecchia A, Fuoco U et al. Autonomic dysreflexia during urodynamics. Spinal Cord 1998; 36: 756-760.

14 Huang YH, Bih LI, Chen GD, Lin CC, Chen SL, Chen WW. Autonomic dysreflexia during urodynamic examinations in patients with suprasacral spinal cord injury. Arch Phys Med Rehabil 2011; 92: 1450-1454.

15 Walter M, Knüpfer SC, Leitner L, Mehnert U, Schubert M, Curt A et al. Autonomic dysreflexia and repeatability of cardiovascular changes during same session repeat urodynamic investigation in women with spinal cord injury. World J Urol 2015; 34: 391-397.

16 Vírseda-Chamorro M, Salinas-Casado J, Gutiérrez-Martín $P$, de la Marta-García M, López-García-Moreno A, Esteban Fuertes M. Risk factors to develop autonomic dysreflexia during urodynamic examinations in patients with spinal cord injury. Neurourol Urodyn (e-pub ahead of print 19 October 2015; doi:10.1002/nau.22906).

17 Krassioukov A, Biering-Sørensen F, Donovan W, Kennelly M, Kirshblum S, Krogh K et al. International standards to document remaining autonomic function after spinal cord injury. J Spinal Cord Med 2012; 35: 201-210.

18 Biering-Sørensen F, Craggs M, Kennelly M. International urodynamic basic spinal cord injury data set. Spinal Cord 2008; 46: 513-516.

19 DeVivo M, Biering-Sørensen F, Charlifue S. International Spinal Cord Injury Core Data Set. Spinal Cord 2006; 44: 535-540.

20 Biering-Sørensen F, Craggs M, Kennelly M. International lower urinary tract function basic spinal cord injury data set. Spinal Cord 2008; 46: 325-330.

21 Schäfer W, Abrams P, Liao L, Mattiasson A, Pesce F, Spangberg A et al. Good urodynamic practices: uroflowmetry, filling cystometry, and pressure-flow studies. Neurourol Urodyn 2002; 21: 261-274.

22 Kirshblum SC, House JG, O'connor KC. Silent autonomic dysreflexia during a routine bowel program in persons with traumatic spinal cord injury: a preliminary study. Arch Phys Med Rehabil 2002; 83: 1774-1776.

23 Ekland MB, Krassioukov AV, McBride KE, Elliott SL. Incidence of autonomic dysreflexia and silent autonomic dysreflexia in men with spinal cord injury undergoing sperm retrieval: implications for clinical practice. J Spinal Cord Med 2008; 31: 33-39.

24 Huang YH, Bih LI, Liao JM, Chen SL, Chou LW, Lin PH. Blood pressure and age associated with silent autonomic dysreflexia during urodynamic examinations in patients with spinal cord injury. Spinal Cord 2013; 51: 401-405.

25 Krassioukov AV, Weaver LC. Episodic hypertension due to autonomic dysreflexia in acute and chronic spinal cord-injured rats. Am J Physiol 1995; 268: H2077-H2083.

26 Perkash I. Autonomic dysreflexia and detrusor-sphincter dyssynergia in spinal cord injury patients. J Spinal Cord Med 1997; 20: 365-370. 